\title{
Application of a Macchinetta Extractor to Solubilize $\beta-1,3$ Glucan in Water
}

\author{
Mikiji Shigematsu, Ryoichi Chuman, Yumi Mizuki and Hiroshi Masamoto \\ Faculty of Engineering, Fukuoka University, Fukuoka 814-0180, JAPAN \\ Fax: 81-92-865-6031, e-mail: shigem@fukuoka-u.ac.jp
}

\begin{abstract}
To solubilize pachyman ( $\beta-1,3$ glucan) in water, the application of macchinetta extractors was investigated. Superheated water of about $140{ }^{\circ} \mathrm{C}$ was generated in the high pressure produced by a pressure building bed constructed of tightly compressed powder of pachyman itself. The superheated water caused hydrolysis of pachyman while passing through the packed bed. The oligosaccharides produced by partial hydrolysis were immediately extracted from the macchinetta without hard damage such as pyrolysis. The extraction was sufficient within $5 \mathrm{~min}$. The highest extract yield was $5.5 \%$ of the raw material and 11 times that from a Soxhlet extractor. The yields increased with an increase of water temperature, which was controllable by varying the packed bed thickness. Furthermore, using moist powder was a practical improvement of the pressure building ability of a packed bed. The extracts obtained were $21 \%$ glucose, $4 \%$ disaccharide and $75 \%$ oligomer. The average molecular weight was $1.6-1.9 \times 10^{3}$, which corresponds to 10-12 degrees of polymerization. In addition, it was confirmed that the elution had bioactivity to the special enzyme extracted from the blood cells of a horseshoe crab. Key words: $\beta-1,3$ glucan, macchinetta, superheated water, hydrolysis, extraction
\end{abstract}

\section{INTRODUCTION}

$\beta-1,3$ glucan (Fig. 1) is a polysaccharide found in mushrooms and has antitumor activity.[1] However, its solubility in water is quite low because of its high polymerization and the formation of triple helix structure in water.[2,3] Therefore, the oral intake of $\beta-1,3$ glucan in a solid state is ineffective.[4]

In this report, to solubilize $\beta-1,3$ glucan in water, the reduction of polymerization by superheated water was investigated. For a simple apparatus, a macchinetta extractor, which is normally used for making espresso coffee, was used in this report. The extraction mechanism is shown in Fig. 2. A packed bed made of powdered material in a basket operates as the pressure building mechanism, and as the pressure in the boiler rises, the water is heated to over $100{ }^{\circ} \mathrm{C}$. At about $140^{\circ} \mathrm{C}$, water causes the hydrolysis of polysaccharide as it passes through the fluid space in the bed. The oligosaccharides produced by partial hydrolysis are immediately extracted from the basket without further hard damage, such as pyrolysis producing organic acids or aldehydes. Finally, we obtain the oligomer of $\beta-1,3$ glucan as a water soluble state.[5] This chemical exchange is schematically shown in Fig. 3.

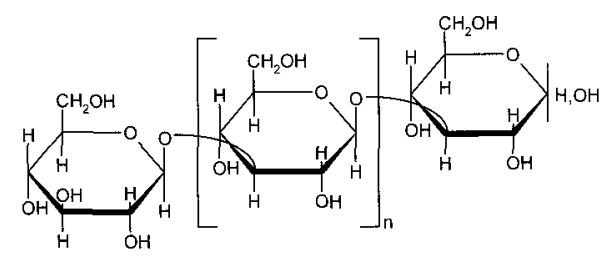

Fig. 1 Chemical structure of $\beta-1,3$ glucan.
This report presents the application of a macchinetta to extract water soluble $\beta-1,3$ glucan, and gives the results of the yield and chemical analyses. The extractive conditions were parameterized by the thickness and initial moisture content of the powder.

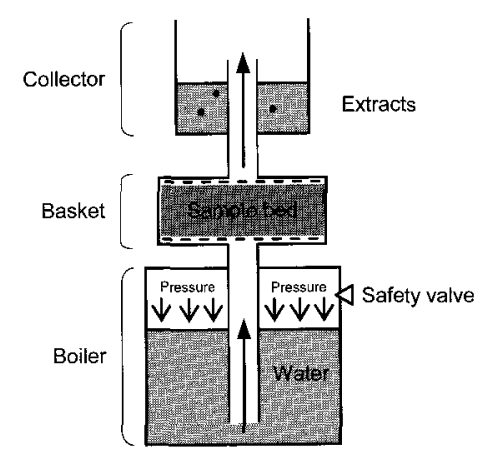

Fig. 2 Mechanism of the macchinetta extractor.

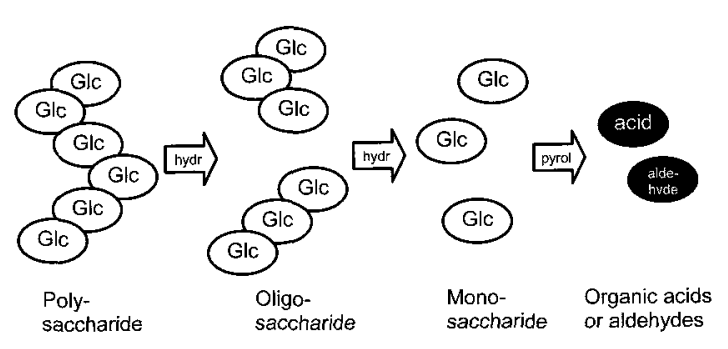

Fig. 3 Chemical exchange of polysaccharide by superheated water.

Glc, glucose; hydr, hydrolysis; pyrol, pyrolysis. 
Table I Extraction of $\beta-1,3$ glucan from poria sclerotium using Soxhlet or macchinetta extractors.

\begin{tabular}{|c|c|c|c|c|c|c|c|c|c|c|}
\hline \multirow[b]{2}{*}{$\begin{array}{l}\text { Run } \\
\text { No. }\end{array}$} & \multicolumn{5}{|c|}{ Extractive conditions } & \multicolumn{5}{|c|}{ Results } \\
\hline & Extractor & $\begin{array}{c}\text { Particle } \\
\text { size } \\
{[\mu \mathrm{m}]}\end{array}$ & $\begin{array}{c}\text { Supplied } \\
\text { material } \\
{[\mathrm{g}-\mathrm{DW}]}\end{array}$ & $\begin{array}{c}\text { Added } \\
\text { moisture } \\
{[\%-D W]}\end{array}$ & $\begin{array}{l}\text { Thickness of } \\
\text { packed bed } \\
{[\mathrm{mm}]}\end{array}$ & $\begin{array}{c}\text { Extract. } \\
\text { time } \\
{[\mathrm{sec}]}\end{array}$ & $\begin{array}{l}\text { Max. } \\
\text { temp. } \\
{\left[{ }^{\circ} \mathrm{C}\right]}\end{array}$ & $\begin{array}{c}\text { Elution } \\
{[\mathrm{ml}]}\end{array}$ & $\begin{array}{l}\text { Sugar } \\
\text { conc. } \\
{[\mathrm{g} / \mathrm{l}]}\end{array}$ & $\begin{array}{c}\text { Extract } \\
\text { yield } \\
{[\%-D W]}\end{array}$ \\
\hline 0 & Soxhlet & $74-177$ & 8.9 & $-\cdots$ & ---- & $4[\mathrm{hr}]$ & 100 & ---- & --- & 0.5 \\
\hline 1 & & $177-250$ & 10.1 & 58 & 7.9 & 180 & 122 & 4 & 10.4 & 0.4 \\
\hline 2 & & $177-250$ & 14.0 & 56 & 11.8 & 160 & 132 & 8 & 13.0 & 0.8 \\
\hline 3 & & $177-250$ & 17.3 & 59 & 15.7 & 105 & 125 & 17 & 10.5 & 1.1 \\
\hline 4 & & $177-250$ & 9.5 & 84 & 8.0 & 54 & 117 & 18 & 5.8 & 1.1 \\
\hline 5 & DeLonghi & $177-250$ & 29.8 & 100 & 29.8 & 70 & 137 & 28 & 13.0 & 1.2 \\
\hline 6 & & $177-250$ & 26.7 & 122 & 29.8 & 60 & 134 & 45 & 8.5 & 1.4 \\
\hline 7 & & $177-250$ & 12.5 & 55 & 11.7 & 180 & 138 & 29 & 6.8 & 1.6 \\
\hline 8 & & $177-250$ & 15.3 & 85 & 16.0 & 70 & 136 & 47 & 5.6 & 1.7 \\
\hline 9 & & $177-250$ & 14.2 & 117 & 15.8 & 70 & 135 & 64 & 4.3 & 1.9 \\
\hline 10 & & $74-177$ & 11.6 & 31 & 12.8 & 300 & 148 & 17 & 12.5 & 1.8 \\
\hline 11 & & $74-177$ & 4.8 & 113 & 6.5 & 300 & 141 & 74 & 1.3 & 2.0 \\
\hline 12 & Electrolux & $74-177$ & 5.8 & 40 & 6.7 & 300 & 145 & 83 & 1.6 & 2.3 \\
\hline 13 & EP930 & $74-177$ & 7.1 & 113 & 9.3 & 300 & 149 & 37 & 4.8 & 2.5 \\
\hline 14 & & $74-177$ & 4.7 & 113 & 6.6 & 300 & 145 & 136 & 0.9 & 2.6 \\
\hline 15 & & $74-177$ & 7.0 & 41 & 8.1 & 300 & 143 & 43 & 8.9 & 5.5 \\
\hline
\end{tabular}

The records are sorted by the extract yields. The extraction time is the period from the start of boiler heating to the finish of the collection of elution. DW, dry weight.

\section{MATERIALS AND METHOD \\ 2.1 Material}

For the raw material of $\beta-1,3$ glucan, poria sclerotium (scientific name, Poria cocos; Japanese name, Bukuryo) was used. This includes over $95 \%$ pachyman, of linear $\beta-1,3$ glucan for the main chain and a very small amount of $\beta-1,6$ glucan for the side chain.[6] Poria sclerotium was milled to a white powder and sieved before applying to the macchinetta extractor.

\subsection{Extraction method}

For the extractor, two kinds of steam-type espresso coffee makers were used in this report; one was a DeLonghi EMK6 and another was an Electrolux EP930. The mechanism for both machines was macchinetta extraction. Hot water passes from a bottom boiler to an upper collector through a sample basket in the former machine, but from an upper injector connected with a side boiler to a bottom collector through a sample basket in the latter machine.

Several grams of powdered sample were placed in the basket and compressed by hand pressing; the same as tamping coffee grounds to make espresso. The basket diameters were $61 \mathrm{~mm}$ and $52 \mathrm{~mm}$ for the EMK6 and EP930, respectively. After connecting the sample basket with a holder to the macchinetta body, about $100 \mathrm{ml}$ of water was placed in the boiler and heated. As the compressed sample itself works as the pressure building mechanism, the water was heated to over $100{ }^{\circ} \mathrm{C}$ and finally reached about $140^{\circ} \mathrm{C}$. Superheated water passed through the sample with water-soluble oligosaccharide produced by hydrolysis. As the elution immediately cooled at the collector to below $100{ }^{\circ} \mathrm{C}$ under atmospheric pressure, the decomposition of extracts halted. The elution was centrifuged to remove insoluble material.

For a comparison with the macchinetta extractors, the extracts were also obtained by 4 hours boiling in water with a Soxhlet extractor.

2.3 Chemical analysis of extracts

Extract yields were measured using the total sugar content with the phenol-sulfuric acid method or by the dry weight of elution. The glucose content in elution was measured using HPLC with a refractive index detector. The molecular weight was measured using the viscosity-molecular weight relationship in DMSO.[7] The presence of $\beta-1,3$ glucan was confirmed by BGSTAR purchased from Maruha Co. Ltd.

To compare the decomposition rates of diglucans, the electrostatic potential charge was calculated by PM3 method in MOPAC2002 built in WinMOPAC 3.9 Pro distributed by Fujitsu Co. Ltd.

\section{RESULTS AND DISCUSSION}

3.1 Yield of extracts

The yields of extracts are shown in Table I. With a Soxhlet extractor (run 0 ), only $0.5 \%$ of the raw material was extracted even after boiling for 4 hours. This was caused by the low solubility of pachyman in water as described in the Introduction. On the other hand, with the macchinetta extractors (runs 1-15), the yields of extracts were several percentages and higher. The higher yields with the macchinetta extractors would be due to hydrolysis at higher water temperatures.

Oomori et al. reported the hydrolysis of many disaccharides in sub-critical water.[8] For example, in many experiments, maltose $(\alpha-1,4$ glucan) and cellobiose ( $\beta-1,4$ glucan) decomposed to glucose at $220^{\circ} \mathrm{C}$ for several hundred seconds. The production of glucose from maltose was faster than from cellobiose. Unfortunately, they did not carry out an experiment on the decomposition of $\beta-1,3$ glucan. We tried to estimate the rate of decomposition of $\beta-1,3$ glucan using the relationship between the rate constant of decomposition and the electrostatic potential charge of the glucosidic oxygen atom proposed by Oomori et al. In our 


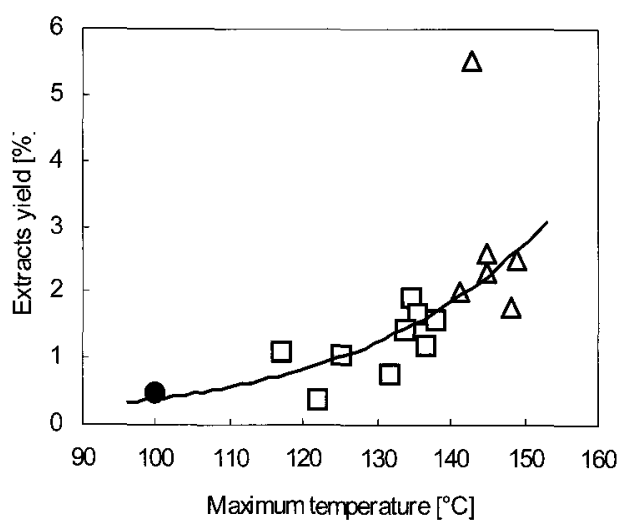

Fig. 4 Relationship between the maximum temperature and the extract yields using various extractors.

, Soxhlet extractor; $\square$, DeLonghi EMK6; $\triangle$, Electrolux EP930.

calculations using the PM3 method, the electrostatic charge at the glucosidic oxygen of $\alpha-1,4, \beta-1,4$ and $\beta-1,3$ glucans were $-0.183,-0.110$ and -0.145 , respectively. These values suggest the rate constant of $\beta-1,3$ glucan may be between those of $\alpha-1,4$ and $\beta-1,4$ glucans. Therefore, it was confidently postulated that $\beta-1,3$ glucan would be hydrolyzed by high-temperature water and the macchinetta extraction method would be shown suitable to produce water-soluble $\beta-1,3$ glucan.

\subsection{Effect of the temperature of superheated water}

Figure 4 shows the relationship between the maximum temperature and the extract yields for the three extractors. The figure shows higher temperatures produce higher yields.

Comparing. these extractors, the yields for the Electrolux EP930 were higher than those for the DeLonghi EMK6. This difference is due to the different maximum temperatures of the superheated water generated in their extractors. The former machine has a tight connection between the basket holder and body, whereas the latter connector relies on hand screwing. Steam leaks from the connector of the DeLonghi EMK6 during superheating; whereas with the extraction with the Electrolux EP930, no leakage was observed. Consequently, the maximum temperatures in the Electrolux EP930 were higher than those in the DeLonghi EMK6 and the hydrolysis was sufficient.

In spite of the different maximum temperatures, both macchinetta extractors gave good extraction compared with the Soxhlet extractor because of the generation of superheated water. The safety valve of the boiler did not open in any of the experiments.

Figure 5 shows the time course of the elution volume and the temperature during macchinetta extraction in run 15. The temperature of the water rose to about $140{ }^{\circ} \mathrm{C}$ after $3 \mathrm{~min}$, and a superheated state was maintained for $30 \mathrm{~min}$. Extraction was almost complete within the first $5 \mathrm{~min}$, and elution was just a little after this. This indicates that macchinetta extraction is fast and efficient.

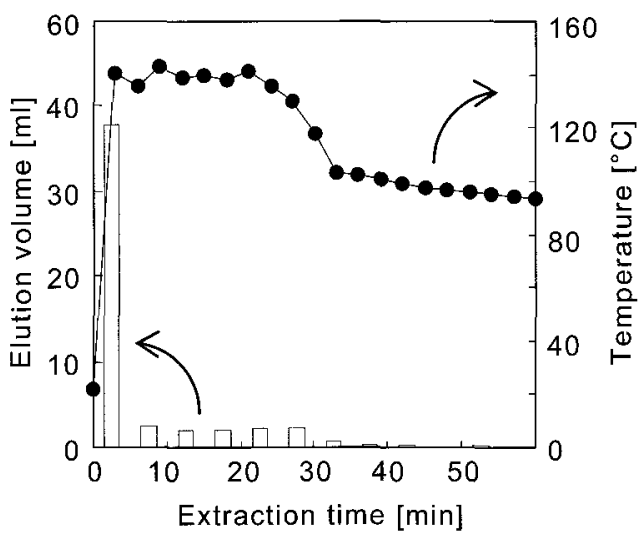

Fig. 5 Example of the time course of the elution volume (bar) and the temperature (circle) during macchinetta extraction in run 15 .

\subsection{Effect of packing on pressure building ability}

As the pressure building ability of the packed bed affects the maximum temperature of the superheated water, the packing conditions were investigated. These were parameterized by the thickness of the packed bed and the moisture added to the raw material powder.

The thickness of the packed bed is important because channeling tends to occur when the packed bed is too thin. Conversely, the choking of fluid space for water occurs in the bed when it is too thick. Often, unsatisfactory extractions were observed (data not shown); that is, inadequate heating of water below $100{ }^{\circ} \mathrm{C}$ because of channeling in the bed due to inadequate packing. This often occurred for thin beds with just a small amount of powder. Therefore, appropriate packing is necessary for good extraction.

Figure 6 shows the effect of packing conditions on the extract yield. It shows the thickness required for good extraction and indicates channeling and choking can be prevented by adjusting the thickness. In the results, about $15 \mathrm{~mm}$ thickness gave good extraction for the DeLonghi EMK6 extractor.

Concerning the influence of added moisture, good yields were obtained with more than $80 \%$ water addition to the dry powder before packing into the basket. This effect may be due to the success of tight compression which builds good pressure. However, the effect plateaued with excessive moisture content causing enough compression. Yields were low when there was low moisture content. This means the packing was insufficient and thus the temperature did not rise. Therefore, some moisture addition is practical for good pressure building. This is similar to espresso coffee extraction in which it is not possible to make a good coffee if the powder stays too dry.

\subsection{Chemical analysis of extracts}

Chemical analysis was conducted on the elution obtained in run 15. The extracts dissolved in the elution contained $21 \%$ glucose and $4 \%$ disaccharide from HPLC analysis; therefore, the extracts contained $75 \% \quad \beta-1,3$ 


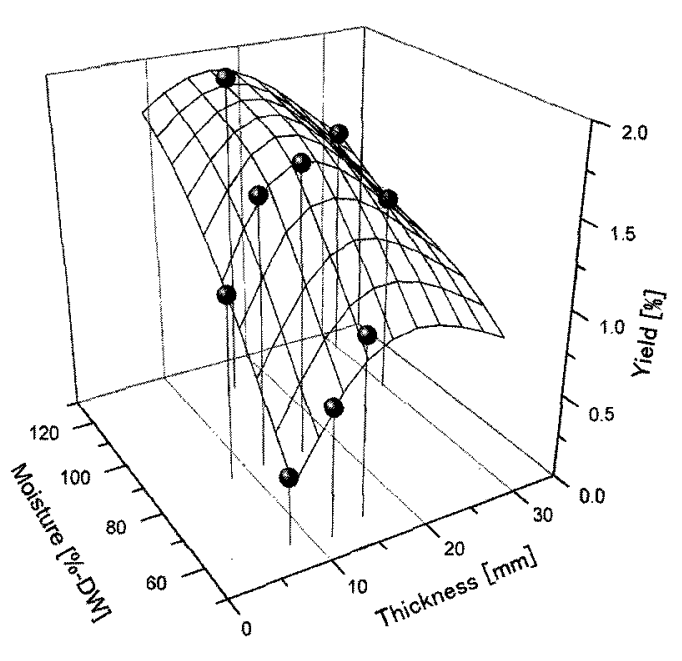

Fig. 6 Effect of the packing conditions on the extract yield in the DeLonghi EMK6 extractor. The balls indicate the experimental data and the curved mesh expresses the tendency of the yield calculated from the experimental data.

glucan as the above trimer. The viscosity averaged molecular weight of the extracts was measured as $1.6-1.9 \times 10^{3}$. This value corresponds to $10-12$ degrees of polymerization. As the molecular weight and polymerization of untreated pachyman were $3.3-5.8 \times 10^{6}$ and $2.0-3.6 \times 10^{3}$, it is considered that the superheated water solubilized pachyman by hydrolysis with a $1 / 2000$ polymerization decrease.

BGSTAR analysis was applied to detect $\beta-1,3$ glucan, and based on the reaction of the special enzyme obtained from the blood cells of a horseshoe crab and $\beta-1,3$ glucan. By applying BGSTAR to the elutions prepared with a macchinetta extractor, the presence of $\beta-1,3$ glucan was clearly confirmed. Consequently, it is expected that water-soluble $\beta-1,3$ glucan oligomer has some bioactivity.

Adachi et al. have reported the reduction of molecular weight of $\beta-1,3$ glucans by heat treatment and noted antitumor activity.[9] They concluded that the molecular weight was decreased from $800 \times 10^{3}$ to $6.4 \times 10^{3}$ by heating in water at $150{ }^{\circ} \mathrm{C}$ for $6 \mathrm{~h}$, and that antitumor activity was reduced. For molecular weight reduction, our results were similar to their report, except for the difference in treatment time. Considering their conclusions about antitumor activity, the water soluble $\beta-1,3$ glucan prepared by us might be antitumor inactive.

\section{CONCLUSION}

To dissolve pachyman in water, partial hydrolysis was carried out in a macchinetta extractor utilizing superheated water. The results showed that the bioactive oligosaccharide of $\beta-1,3$ glucan was produced after a very short extraction time of less than $5 \mathrm{~min}$, with yields being 11 times that extracted using a Soxhlet extractor.

Acknowledgment

We thank Prof. Mitsuhiko Tanahashi, Gifu University, for providing the raw materials and for helpful discussion.

References

[1] G. Chihara, J. Hamuro, Y. Maeda, Y. Arai and F. Fukuoka, Nature, 225, 943-944 (1970).

[2] T. L. Bluhm and A. Sarko, Biopolymers, 16, 2067-2089 (1977).

[3] C. T. Chuah, A. Sarko, Y. Deslandes and R. H. Marchessault, Macromolecules, 16, 1375-1382 (1983).

[4] T. Yadomae, " $\beta$-glucan no miryoku (in Japanese)", Toyoigakusha, Tokyo (2000).

[5] M. Shigematsu, H. Masamoto and Y. Mizuki, Production method of oligosaccharides, Japanese Patent 2007-019030 (Jan/20/2007).

[6] G. C. Hoffmann, B. W. Simson and T. E. Timell, Carbohyd. Res., 20, 185-188 (1971).

[7] H. Futatsuyama, T. Yui and K. Ogawa, Biosci. Biotechnol. Biochem., 63, 1481-1483 (1999).

[8] T. Oomori, S. H. Khajavi, Y. Kimura, S. Adachi and R. Matsuno, Biochem. Eng. J., 18, 143-147 (2004).

[9] Y. Adachi, N. Ohno, M. Ohsawa, S. Oikawa, T. Yadomae, Chem. Pharm. Bull., 38, 477-481 (1990).

(Recieved June 6, 2008 ; Accepted September 5, 2008) 